\title{
INITIATING AN INVESTIGATION FOR CRIME OF MURDER
}

\author{
Natasha Georgieva \\ University MIT, Faculty of Security, Skopje \\ natashageorgievaivanovska@gmail.com
}

\section{Original Scientific Paper \\ doi:10.5937/jouproman8-24734}

\begin{abstract}
In the paper below, are shown the principles that are intended to present the procedure for initiating an investigation into the crime of murder. Through these principles, detectives and chief investigators at the crime scene are able to thoroughly verify and exaggerate all facts that can be, or that are relevant to the investigation. The first information is usually transmitted to detectives or investigators through police stations.
\end{abstract}

The paper further explains the procedures that follow upon arrival at the place where the body was found. Then, the time of arrival, the exact address of the location, the persons present, body condition and position, cause of death information, weather conditions, lighting if night, as well as places of arrival are noted, and fully observation is made in manner of location of possible eyewitnesses or persons who could see what happened, possible location of video surveillance, such as bank cameras, super markets, parking lots, etc.

Among the duties of a detective upon arriving at the scene include an initial interview with the responsible police officer, interviewing medical personnel, dealing with curiosity observers and eyewitnesses at the crime scene. Following this stage, the search follows as an important research tool. In the case of murder with rape, a thorough initial medical examination is performed at the scene.

The chief investigator and the detective in charge of the murder investigation have complete control of the scene. The alleged detective and the murder investigator face a complex problem, so they need to consider motives, manner of execution, and various physical evidence. From here, teamwork is crucial to the success of the investigation.
Keywords: homicide, investigation, information, inspector, detective, investigator, crime scene

\section{Introduction}

The purpose of this article is to provide detectives working on homicide investigations with more flexible guidance in the pre-trial investigation. The principles set out in this section are intended to help detectives and crime scene investigators thoroughly verify and redress all facts relevant to the investigation.

This paper will cover the sequence of events, starting with the initial note of detectives that a murder has taken place, and then proceeding with the directions of action at the scene, including conversations with uniformed persons, conversations with the first officer, with ambulances, dealing with with curious observers and possible eyewitnesses, detail search and an initial medical examination. Additional sections of this chapter will explain the specific investigative methods performed on site. However, this initial phase of the homicide investigation is the most critical and deserves much attention, as it lays the groundwork for an overall investigation. 
The homicide investigation in this paper, will describe the duties of investigators that work on investigating homicide. Those duties are to: observe, describe, record (take notes, take pictures, record video, etc.), collect.

\section{Initially Receiving Information}

Investigating homicides is probably the most important thing that criminologists face. It starts with the initial information that a murder has taken place (Geberth, 1983).

Investigators are rarely the first that arrive at the scene of the murder. Usually, the body is discovered by friends, relatives or citizens, who immediately inform the police and call an ambulance. The information of detectives or investigators is usually transmitted through police stations (Rapp, 1987).

The investigation of the murder investigator and the surveillance supervisor must be methodological. In order not to overlook something that is obvious, the most basic details should be recorded. Many times the wrong assessment of the urgency and / or the desire to take swift action investigators can overlook important details. They may lose the composure needed to take control and conduct an investigation. An important thing to keep in mind is that the victim is not going anywhere and more importantly that the patrol officers are already at the scene, carrying out an initial inspection (O'Hara and O'Hara, 1981).

Priority at the scene is to secure the location, to keep all eyewitnesses and suspects, to prevent the use of telephones near the scene, to obtain personal data of all persons who had access to the scene, write all license plate numbers and information for all vehicles in the vicinity of the scene (Garner, 1987).

It would be good to provide (if possible) pictures of people in the crowd. Often, eyewitnesses to the event, including possible suspects, observe the measures taken by police at the scene. Usually upon arrival of investigators who may recognize some of the previous perpetrators of crime, some in the crowd may disappear.

\section{Arriving at the crime scene}

When the inspector arrives at the crime scene he should note the following: time of arrival, exact address of the location, persons present (police officers, relatives, medics, friends, etc), condition and body position, information on causes of death, weather conditions, night time illumination, observation sites (location of possible eyewitnesses or persons who could see what happened), possible location of video surveillance (bank cameras, super markets, parking lots, etc.) (O'Hara and O'Hara, 1981).

The following is a list of initial steps by detectives upon arriving at the scene (Rapp, 1987).:

$\checkmark$ Restrict place immediately upon arrival. No unnecessary movement in the circle.

$\checkmark$ Decide how to access the site. Ensure entry and exit from the site.

$\checkmark$ Perform an initial tour. Using this opportunity allows one to develop a mental image and to "capture the scene of the crime". 
$\checkmark$ If there is a presence of fragile evidence, it must be collected.

$\checkmark$ Prior to any inspections, is taking photographs in order to prevent evidence from being filed.

$\checkmark$ Note the air temperature.

Further, the inspector should observe the site thoroughly, taking note of everything possible before entering the scene for further examination. Only he and the detective can enter the scene of the crime, with the exception of the competent police officers, only to ascertain the death and to ascertain the conditions in which it occurred. Investigators should note the time and place of the murder, as well as other important evidence. There are three reasons for taking these first remarks (O'Hara and O'Hara, 1981):

1. Timing is the first question to be asked during questioning. If the inspector cannot be sure of the timing of the murder, he may lose the credibility of further testimony.

2. Time can be the basis for alibi.

3. Taking notes will slow down the inspector. That's why he talk with a lower tone at the crime scene and also allows for attention on details and note them.

\section{Description of the crime scene}

The complete description of the dead body and the environment covers the following points, which should be entered on the inspector's report upon arrival (Brussel, 1968):
1. Include in the record the sex, appearance, age, structure, color of the victim's hair and description of the victim's clothing.

2. Make a list of injuries and obvious causes of death.

3. Whether the blood stains are dry or wet.

4. What is the condition of the body (possible bruising on the body, stiffness ...).

5. Describe the blood color, light red or brown.

6. Notice whether the clothing is torn and any possible traces of shots or stings.

7. Carefully examine the hands for any wounds or weapons.

8. Are there any jewelry (rings, watches, gold chains. If not, notice it. The defense is usually known for its dirty tactics during trials. If they can make someone to look like a thief they will do it in order to discredit the eyewitness testimony.

9. Describe the nearest surroundings: a) note the position of the body relative to the objects in the room and b) note the locations of doors, windows, furniture...

10. If there are weapons in the vicinity, detailed data should be obtained and should not be touched.

11. Look for bullet holes or cracked bushes. If any, do not collect at this stage of the investigation.

12. In case of death due to poisoning and drug overdose it is necessary to note the presence of drugs, bottles or cups. 


\section{Implementation of the procedure at the crime scene}

The first thing that inspector should do to after determination of the death, is to secure a crime scene. In the absence of surveillance by a detective, the homicide detective is responsible for a professional investigation. Therefore, special attention should be paid to the protection of the crime scene, as even the smallest details can prove to be key to resolving the case (Anderson, 1987).

Failure to properly implement the techniques can lead to disruption to the investigation process. If the murder is in the open area, then a wide cordon around the body needs to be secured, then all subsequent investigations are undertaken. If the murder is indoor, securing the location is relatively easy, with one simple door closure. The inspector should determine which places to include or exclude as a crime scene and decide whether the murder involves more places of execution (Geberth, 1983).

\section{Direction of action of the uniformed persons at the crime scene}

The chief investigator and the detective in charge of the homicide investigation have complete control of the scene. They have full authority to exclude everyone, including other police officers, the media, and any other unauthorized person other than a medical investigator. Often traces of evidence have been found to have destroyed important evidence due to the presence of many police officers (Geberth, 1983).
Actions such as standing or moving at the scene or leaning against doors and walls can cause the destruction of important evidence, such as fingerprints, blood, hair or parts of the skin.

Sometimes superiors can inadvertently destroy important evidence. Sometimes the patrol officer will be able to provide evidence before investigators arrive. In many situations, police officers can provide evidence, such as firearms, for the security of the situation. They should be able to properly preserve this evidence, to properly record the data, so that these same materials can later be used as evidence (O'Hara and O'Hara, 1981).

\section{Teamwork approach}

The alleged detective and the murder investigator face a complex problem, so they need to consider motives, manner of execution, and various physical evidence. From here, teamwork is crucial to the success of the investigation and the chief detective (investigator) and homicide investigators must find common approach and teamwork, coordinate the distribution of the people involved and responsible (Rapp, 1987).

\section{Detective duties upon arriving at the scene}

Upon arrival, the detective or chief inspector should assume responsibility for leading the investigation for the murder and replace the existing investigator at the scene responsible for the case. It is important that those responsible for leading the case to do not fall into a specific, routine procedure. 
Previous experience is welcome, but it can also be resistant to inserting new moments into separate investigations. It is also necessary to know that each murder is unique in itself and may require fresh access or open vision (Brussel, 1968).

Practically, at this level of investigative action, no one can have all the answers and no one can accurately know the direction of the case. However, the competent authority should be guided by certain basic procedures at the scene (Garner, 1987).

1. Establish that the investigator has arrived at the crime scene and that it is sufficiently protected.

2. Cooperate with the responsible uniformed police officer who provides information for the case.

3. Prioritize the removal of suspects and/or eyewitnesses, ie their removal to a police station.

4. Signed statements should be used, which will identify who took and gave statements, at what place and time, and thus eliminate any duplication.

5. If the communications center is not notified by the patrol police, the investigator shall take urgent measures to inform them.

6. It is necessary to designate a police officer to keep track of the time of events, including arrivals and departures from the scene.

7. If the victim is transferred to a hospital, it must be ensured that appropriate measures are taken in the hospital that provide any statements made prior to the occurrence of death, the provision of laundry and other evidence.
8. If the suspect fled the scene, the investigator and the responsible inspector must be notified. After verification and receipt of any new information, it should be transmitted.

9. Ensure dissemination of information to all units involved in the investigation.

10. In case if too many police officers appear at the crime scene, the responsible inspector should not hesitate to instruct these police officers to return to their essential duties if not required here.

\section{Initial interview with the responsible police officer}

The detective must make sure that the scene is untouched, that is, nothing has been added or removed since the time the police arrived. Detectives should have a detailed overview of what police officers have seen and acted on so far. Often the opinions of the responsible police officers provide a significant advantage in the investigation (Geberth, 1983).

It is recommended that the first police officers arriving at the scene respond to some questions related to the appearance of certain items when they arrived, and report any observations by persons who were not at the scene, or persons who showed interest for the work of the police. 


\section{Interview with medical staff}

Usually the medical staff is the first to arrive at the scene of the murder. Sometimes paramedics can be of great help for detectives, because it is their duty to inspect the body and provide medical assistance if the victim is still alive. Often the thug is still at the scene and can even help the medical team. It may happen that the victim has spoken the name beforehand or given the description of the abuser (Anderson, 1987).

Also, many people who were present at the attack will not leave when the ambulance arrives, but will stand around. Once the police units arrive, these people will suddenly become frightened. Every detail of their actions should be known. They need to answer questions such as: Who was present? Did the deceased say anything? Did they smoke? If they smoked whether they threw their rubbish and where they threw it.

\section{Handling curiosity observers}

The use of courtesy and humble professionalism in dealing with the civilian crowd can be helpful. Co-operation with the police assistance crowd may be used while securing the site and possibly assist with some useful information. Not to get into verbal rhetoric with people from the crowd. Dealing with curious observers from the crowd we will never know who has the information and who will deliver it. Here it is recommended to hire someone who does not look like detectives to infiltrate into the crowd.

\section{Dealing with eyewitnesses at the crime scene}

Also, the scene of the murder offers ample information and evidence, and the identity of the murderer is often revealed through intelligent interrogation of witnesses.

The investigating detective should reveal the identities of all eyewitnesses found at the crime scene. Valid identification includes name, date of birth, address of residence and work (with postal numbers and telephones), and all of this should be included for further contact if required in further investigation. It is important that eyewitnesses are separated, and that each of them is questioned individually as soon as possible after the event. The location of the conversation and the formal statement of the witness should be in an office where there will be privacy and equipment for recording the conversation if possible (Anderson, 1987). The formal statement should be taken and each witness questioned separately by the investigating authority. There is a problem with investigative actions when one of the witnesses does not speak the language spoken in the state, so it will be necessary to provide an interpreter who knows the witness's language. The eyewitnesses must be allowed to calm down and speak a little about themselves. They should be encouraged to relate what happened in their own words. Effective questioning is an art that requires constant proof (Geberth, 1983). 


\section{Search}

The search, among other things, includes a brief conversation with people on the street, from whom investigators thought they could extract some information related to the particular incident. The search is an important investigative tool and is a vital part of the initial crime scene investigation. Investigators are required to conduct an initial search of the area surrounding the crime scene, including access and escape routes (O'Hara and O'Hara, 1981). While detectives are conducting the search, their primary purpose should not be to conduct in-depth interviews, but simply to locate potential witnesses or persons who have background information about the crime being investigated. Since it is envisaged that too much information is to be obtained during the investigation, it is desirable that anyone involved in the investigation keep their own log of events containing the relevant and necessary information relevant and related to the case. Every home, area or person searched should be recorded in the notebook of the investigators involved. Many homicides are highlighted as a result of a well-conducted search conducted by a select group of searchers who discovered some vital information, including motive and even an eyewitness (Geberth, 1983).

A properly conducted search is a very important investigative technique that can provide: specific crime eyewitnesses, information about the circumstances of the crime, approximate time of occurrence and/or estimation of time of death, information on the deceased's identity, habits, friends, as well as motives for crime (Garner, 1987).

\section{Initial medical examination at the scene}

In the case of homicide, the medical examiner, or the forensic examiner, is responsible for conducting an investigation to determine the causative mechanisms and circumstances for the death.

The coroner's medical examination should not be carried out before or during the photographing and sketching of the crime scene by the police. If the coroner's medical team arrives before the police, it is necessary to refrain from investigating until the police have taken a photo and taken appropriate action to document and complete the crime scene (Garner, 1987).

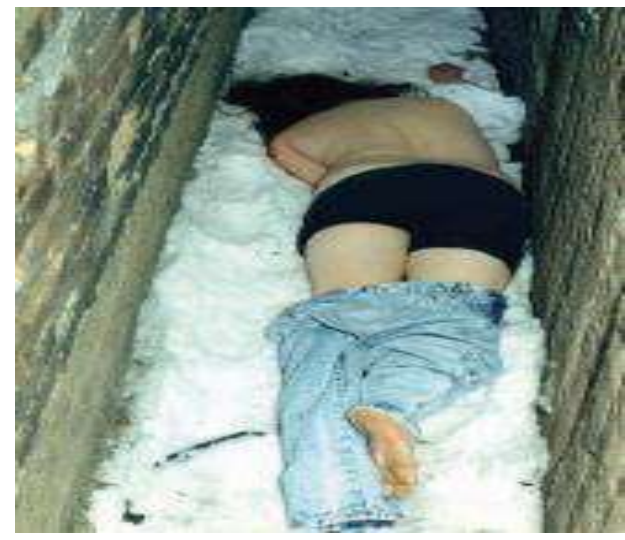

Figure 1. Initial medical examination at the crime scene. 
The first photo shows a body photo taken at the crime scene. According to the pictures, death seems to be related to the sexual abuse of the victim (rape). The second photo shows a forensic investigator doing an initial examination at the crime scene, which proves drowning.

Forensic (medical) investigators can find the following at the crime scene (Brussel, 1968):

1. The cause of death, related to injuries sustained as a result of a stab or shot, may be determined at the scene.

2. Whether the injuries were inflicted before or after the death.

3. Whether the deceased fell or pushed other objects at the crime scene after the injury, which may be the cause of the injuries.

4. Did the body fall on any particular subject, and the pressure caused the injury to the body, which may also be the cause of death.

5. Determine approximately the time of death according to body heat, stiffness of body, bruising of the body, etc.

\section{Special procedure for specific cases}

It is recommended, in certain cases, that the forensic investigator be required to remain at the crime scene during the conduct of the investigative process in order to detect crucial microscopic evidence that could be lost during movement or transport of the body. These specific types of cases are usually related to sex-related homicides, or homicides in which the assailant pierces, cuts, drills or tears at the victim's intimate organs. These cases include extraction, burning, genital displacement of men and women, as well as breast removal of female victims, and include body posture, insertion of objects into openings in the body, and other forms of sexual recovery (Geberth, 1983).

These events are caused by the invader's haunted fantasies. It is not enough for these killers just to kill, but they also have an inner need to bring their painful fantasies, which are the product of their sick minds, onto the victim's body. Through this, their horrific activities on the victim's body, microscopically, provide evidence. If the body is moved or removed from the crime scene, the key evidence can very easily be lost, mixed or destroyed.

\section{Conclusion}

The best advice for detectives working to elucidate crime at the crime scene is to coordinate with medics conducting a medical investigation, discussing theories, and asking questions. If a particular term cannot be understood, it is necessary to ask the physician to explain it in the vernacular. These medical professionals can give advice, which covers the medical aspect of the case and can later provide an opinion from the post mortem examination and the results of the toxicological analysis. The detective and the investigator should seek their advice. 
Historically, forensic doctors have been well-versed in working with people investigating the murder, and this experience is based on professional correspondence and co-operation between them, which leads to a positive case resolution. In many places where crime or murder has occurred, the forensic medical team has been more than helpful to the murder investigator by answering questions that arise from the beginning of the interrogation. Doctors who specialize in forensics usually have a keen interest in murder-related cases. They are often helpful in reconstructing the event and formulating the sequence of events. Because their investigation is directed directly at the circumstances under which the death occurred, the manner in which the deaths that they determine are crucial to a murder investigation. Every professional is aware of the abilities of others, so working together and sharing information can usually come to a joint decision on what actually happened.

\section{Literature}

1. Burt Rapp, (1987), Interrogation: A Complete Manual, Port Townsend, WA, Loompanics Unlimited.

2. Charles E. O'Hara and Gregory L. O'Hara, (1981), Fundamentals of Criminal Investigation, Springfield, IL, Charles C. Thomas, Publisher.

3. Gerald W. Garner, Chief, (1987), The Reporters Are Here, Springfield, IL, Charles C. Thomas, Publisher.

4. James A. Brussel, (1968), Casebook of a Crime Psychiatrist, M.D. New York, Dell Books.

5. Vernon J. Geberth, (1983), Practical Homicide Investigation, New York, Elsevier Science Publishing Co. Inc.

6. William Bryan Anderson, (1987), Notable Crime Investigations, Springfield, IL, Charles C. Thomas. 